Review

\title{
Acute Abdominal Disorders in Dairy Cattle: What Can Clinicians Do under Field Conditions?
}

\author{
Rodrigo Muiño $(\mathbb{D}$, Joaquín Hernández *(D) and Cristina Castillo $\mathbb{D}$ \\ Department of Animal Pathology, Faculty of Veterinary Medicine of Lugo, University of Santiago de Compostela, \\ 27002 Lugo, Spain; rodrigomuino@colvet.es (R.M.); cristina.castillo@usc.es (C.C.) \\ * Correspondence: joaquin.hernandez@usc.es
}

\begin{abstract}
Acute abdomen (AA) is the term used to define a pathological condition that affects the abdominal cavity and frequently manifests itself with acute clinical symptoms capable of compromising a cow's life. Therefore, it should be considered as an emergency that should be evaluated as quickly as possible to adopt the appropriate therapeutic measure (medical or surgical). In an AA situation, the clinician must consider the appropriate diagnostic approach as well as the therapeutic choice. Given the emergency, the veterinarian's experience will be decisive for the appropriate resolution. In this article, we briefly review the causes that may lead to this condition, as well as the different diagnostic tests available in field conditions to establish the correct diagnosis and treatment.
\end{abstract}

Keywords: acute abdomen; emergency; dairy cows

check for updates

Citation: Muiño, R.; Hernández, J.; Castillo, C. Acute Abdominal Disorders in Dairy Cattle: What Can Clinicians Do under Field Conditions? Ruminants 2021, 1, 46-57. https://doi.org/10.3390/ ruminants1010004

Academic Editor: Silvia Preziuso

Received: 23 June 2021

Accepted: 27 August 2021

Published: 31 August 2021

Publisher's Note: MDPI stays neutral with regard to jurisdictional claims in published maps and institutional affiliations.

Copyright: (c) 2021 by the authors. Licensee MDPI, Basel, Switzerland. This article is an open access article distributed under the terms and conditions of the Creative Commons Attribution (CC BY) license (https:// creativecommons.org/licenses/by/ $4.0 /)$.

\section{Introduction}

Cow's milk has been an important part in the food culture for more than 2000 years. When human beings learned to domesticate cattle to take advantage of the multiple properties of their milk, it became an economic source for many people, converting it into an industrial sector.

Therefore, regardless of the development of biotechnology in this field, cow lactation continues to be a vital physiological period in the maintenance and prosperity of a farm. However, the cow must be controlled from a medical and nutritional point of view, so that it can produce high-quality milk while keeping its health and well-being.

Nevertheless, this does not prevent the lactating cow from suffering alterations on some occasions. One of them is known as an acute abdominal disorder. In dairy cattle, the highest emphasis has been placed on studies related to mastitis and diseases of the reproductive tract and hooves. However, information on abdominal diseases is scarce in the veterinary literature [1].

Acute abdomen (AA) is the term used to define a pathological condition that affects the abdominal cavity and frequently manifests itself with acute clinical symptoms capable of compromising a cow's life. Therefore, it should be considered as an emergency that should be evaluated as quickly as possible to adopt the appropriate therapeutic measure (medical or surgical) [2-4].

This condition includes a large number of different disorders that cause abdominal pain and distension, creating discomfort for the cow. These clinical signs, however, can be caused by digestive, renal, or reproductive structures (Table 1).

The sensation of pain from the parietal peritoneum travels through the peripheral spinal nerves and is usually localized over the affected area. This pain is exacerbated by pressure on the area, so the cow is reluctant to move and has a reflex tonic contraction of the abdominal muscles. In the case of visceral pain, some nerve endings are located in the submucosa and muscle layers of hollow viscera, such as the intestine or bladder, and in the capsule of solid organs (kidney, liver). They transmit the painful sensation through the sensory pathways of the autonomic nerves, generating a diffuse pain that is difficult 
to localize. The clinical manifestations, in this case, are very intense: the animal kicks its abdomen, steps on its hind legs lie down, or stands up and stretches.

Table 1. Causes of acute abdomen and common physical examination findings [5].

\section{Gastrointestinal Visceras \\ Disease}

Abomasal volvulus

Hemorrhagic jejunitis

Intussusception

Mesenteric torsion

Paralytic ileus

\section{Non Gastrointestinal Visceras Disease}

Uroliths

Pyelonephritis

Uterine torsion

\section{Common Clinical Signs}

dehydration, tachycardia, tachypnea, bruxism, skin is cool, rarely colic, pulse is weak and thready, faeces are absent or watery but scant, abdominal distension, greater on the right side, large area of tympanic resonance on the right extending from the eighth rib to the middle of the paralumbar fossa.

reduced appetite and milk production, ketosis, faeces are often normal to softer than normal but reduced in volume, ruminal contractions decreased to absent, the last one or two ribs on the left are sprung but the abdomen is sunken in the paralumbar fossa, large area of tympanic resonance (ping) in left cranial abdomen.

variable dehydration, tachycardia, tachypnea, cool extremities, \pm fever and hypothermia in advanced cases, early-stage colic, auscultation of fluids sounds on right, hemorrhagic diarrhoea.

dehydration, tachycardia, tachypnea, \pm pale mucous membranes cool extremities, \pm severe colic, right sided ventral abdominal distension and generalized in advanced cases, auscultation of multiple areas of tympanic resonance over right abdomen, bloody and scanty faeces on rectal examination.

colic severe, tachycardia, tachypnea, rapid debilitation and progression to moribund state, inability to stand up, examination rectal: multiple loops of distended small and large intestine, no faeces.

tachycardia, tachypnea, variable hydration status, variable colic: may be severe, moderate abdominal distension in lower right abdomen, small areas of tympanic resonance, auscultation reveal fluids sounds in right sided abdominal.

\section{Common Clinical Signs}

lethargy, reduced appetite or anorexia, straining to urine, mild colic, hematuria, and it can evolution to ruptures urethra or bladder.

anorexia, fever, dehydration, colic, frequent urination, straining to defecate, dysuria, hematuria, \pm stranguria, exudate adherent to vulvar hairs, rectal palpation: enlarged left kidney.

tachycardia, tachypnea, signs of impeding parturition without progress, mild colic, vaginal examination: circumferential constiction of vaginal wall, rectal examination: torsion of the uterine ligament is palpated.

Many of the reports available in the literature refer to diagnostic and complementary methods (such as laparotomy) carried out in specialized facilities that are often far from livestock farms. It is also important to take into account that the farmer cannot always assume the cost of transport and hospitalization of the animal. Therefore, the resolution of the problem in situ is of vital importance.

To establish an accurate diagnosis, we should do an exhaustive clinical history together with a detailed clinical examination Table 1, choosing proper ancillary tests. In the case of acute pain, the diagnosis should be made urgently, selecting the least invasive technique possible that would offer the best results, according to the cost-benefit ratio, being sometimes necessary, as a last resort, to do a laparotomy. Nevertheless, we have avoided unnecessary complementary tests that would increase the cost and delay the resolution of the case, worsening the critical condition of the animal.

The main objective of this article is to offer a simple and realistic methodology that will help veterinarians to act when attending a cow affected by this process. 


\section{Predisposing Factors to the Development of Acute Abdominal Syndrome}

Age, breed, nutrition, and lactation stage are relevant parameters to take into consideration when evaluating a cow with AA. Thus, the type of aptitude of the cow is important: dairy cows, strictly speaking, are more predisposed to suffer from displacement or abomasal volvulus than lactating cows destined for meat production [6]. In relation to physiological stage, uterine torsions are normally observed at the time of parturition or during the dry period [7]. In addition, recent estrus could be associated with hypocalcemia, which results in paralytic ileus [8].

Nutritional management also predisposes to AA signs. For example, if a dairy cow is fed with highly non fermented energy-rich carbohydrates after the early lactation stage, a subacute ruminal acidosis with signs of abdominal pain can be developed [9].

It is during the periparturient period, particularly during the first two months of calving, that cows have been reported to be most vulnerable to the development of caecal dilatation. This is due to the fact that high milk yield demands the consumption of more concentrates, which leads to an increased production of volatile fatty acids (VFA's) [10]. The high level of VFAs produces the accumulation of gases. This, in turn, produces atony which leads to cecal dilatation and subsequent dislocation [10]. Winter season has been found to be an important predisposing factor the occurrence of caecal dilatation [11].

As regards infections, one of the most problematic ones is jejunal hemorrhage syndrome (JHS) which is an acute, highly fatal enterotoxemic disorder in dairy cattle. Multiple descriptive names have been proposed for this condition, including hemorrhagic bowel syndrome, acute hemorrhagic enteritis of the small intestine, bloody gut, or JHS. The cause is uncertain and the pathogenesis poorly understood. Nevertheless, Clostridium perfringens type $A$ has been strongly suggested as a primary etiologic agent [12]. Other authors, however, have reported an association between JHS and infection with Aspergillus fumigatus [12]. This infection has been frequently reported during the last few decades in all regions in the United States and some European countries [13], especially in the autumn and winter months [14]. In addition, approximately $60 \%$ of the cases occur within the first 100 days of lactation and another $20 \%$ of the cases occur during midlactation. More than $90 \%$ of reported cases occur during the second lactation and in older cows [13]. The high incidence take place early during lactation, when a cow's milk production and feed intake are both relatively high. Therefore, it could be associated with nutritional factors. In fact, feeding a high-energy diet has been found to increase the risk of developing JHS [12].

\section{Health History and Physical Examination}

When we go to a farm because the farmer informs us of a dairy cow that shows signs of pain, making a complete anamnesis is mandatory for the clinician to correctly approach the clinical case. Hence, collecting the description of the clinical signs and their evolution, from the owner's point of view, is of vital importance. Faecal output, consistency, and appearance are valuable information. Faeces that present mucus, blood, dark colour, and fetid odour are characteristic of gastrointestinal disease [1].

The nutrition programme and management system are important parts of the clinical history as a poor nutrition programme and/or an incorrect management system can lead to subacute ruminal acidosis after parturition, which, in turn, can provoke abdominal discomfort [5].

Moreover, previous treatments should also be noted. We should act as if the animal has been under clinical procedures. For example, if any obstetric (insemination) or surgical manipulations have recently been performed, as this might indicate that the animal suffers from peritonitis.

Physical examination should include the determination of rectal temperature, pulse, heart rate, respiratory rate, capillary refill time, and degree of dehydration. In the case of acute pain, heart rate, and respiratory rate increase, the pulse may be weak and capillary refill time increases if hypovolemia is present. 
Rectal palpation is a basic tool in the physical examination since it allows us to differentiate between gastrointestinal, reproductive, and renal processes [4]. For example, if we are dealing with a case of cecal dilatation-torsion, this exam allows us to detect the situation of the apex of the cecum and its orientation, which allows us to differentiate whether it is a simple dilatation or a torsion [4]. We can also palpate distended and firm bowel loops, which may be indicative of intussusception [14]. The presence of fresh blood mixed with stool may suggest hemorrhagic jejunitis or intussusception $[15,16]$.

Uterine torsion is detected by rectal and vaginal examination [17]. Pyelonephritis suspicion is determined by examination of the left kidney via the rectum, combined with urine evaluation by dipstick and diagnostic imaging tests to confirm the diagnosis.

\section{Complementary Examination Methods}

Complementary tests are useful for three reasons: (a) they provide us with information on the urgent problems of the patient to stabilize it (b) they help us diagnose the cause of the AA (c) they help us to establish the evolution and prognosis of the diagnosed pathology.

\subsection{Blood Tests}

The main problem with this type of analysis is that the results are not immediately available, especially if the sample is collected on a farm that is far from a laboratory. Therefore, it is essential to have portable analysers that assess key parameters, such as basic hematological, acid-base balance, or biochemical key values.

\subsubsection{Haematological Findings}

Hematologic assessment is used to determine the severity of the process. An elevated erythrocyte count indicates hemoconcentration and dehydration due to fluid sequestration in the gastrointestinal tract, the presence of septic shock, or toxemia [18]. If we find a marked decrease in erythrocyte and serum protein counts, we can suspect the existence of an abomasal ulcer, JHS, or peritonitis [5,7]. In short, the erythrocyte count and serum total proteins serve as indicators to evaluate the response to medical treatment of AA.

Concerning inflammatory cell counts, in most cases, the acute abdomen causes minimal to moderate inflammation manifested by leukocytosis or moderate neutropenia. In severe sepsis, marked neutropenia and lymphopenia may be observed. Dos Santos et al., [1] found leukocytosis by neutrophilia with a regenerative left shift in focal or diffuse peritonitis.

\subsubsection{Biochemical Findings}

Based on the availability of portable analysers, there are several biochemical parameters of great interest under field conditions. One of these parameters is L-lactate [19]. L-lactate is a well-established biomarker of tissue hypoxia, sepsis, and severity of diseases such as right-sided abomasal disorders, hemorrhagic bowel syndrome, intestinal intussusceptions or strangulations, and peritonitis. Therefore, the measurement of this metabolite has attracted increasing attention in bovine medicine [20]. Systemic or peripheral hypoperfusion due to hypovolemia, the presence and extent of hypovolemic shock, and the presence and extent of potential gastrointestinal ischemia are all considered mechanisms for hyper-L-lactatemia due to insufficient tissue oxygen supply. It might also be relevant in case of surgery $[21,22]$. Adrenergic stimulation by catecholamines, associated to stress due to pain can be an additional cause of clinical hyper-L-lactatemia.

Other parameters are chloride and potassium. Hypochloremia, hypokalemia, and metabolic alkalosis [12] are common findings in cases of abomasal volvulus, intussusception, cecal dilatation, peritonitis, renal disease, gastrointestinal stasis, intestinal obstruction, or gastrointestinal reflux, due to sequestration of both electrolytes at this level. On the other hand, metabolic acidosis occurs in some renal diseases, enteritis, or strangulation of the small intestine [23]. 
Several studies have used chloride, potassium, and lactate as prognostic indicators before and after surgery for the right abomasal volvulus. Chloride concentrations $<85 \mathrm{mmol} / \mathrm{L}$ and lactate concentrations $>6 \mathrm{mmol} / \mathrm{L}$ are associated with poor prognosis after surgery [24-26].

Acute phase proteins such as fibrinogen, haptoglobin, or serum amyloid have been successfully used for the differential diagnosis of traumatic peritonitis [27]. Moderately increased fibrinogen concentration, together with a marked decrease in total plasma proteins may help in the diagnosis of peritonitis [4].

Bilirubin and the enzyme gamma-glutamyl transpeptidase (GGT) are increased in cholestasis. Urolithiasis and pyelonephritis would be confirmed by the presence of elevated blood urea and creatinine levels.

\subsection{Abdominocentesis: Assessment of Peritoneal Fluid}

Abdominocentesis and peritoneal fluid (PF) analyses proved as an effective tool in the routine clinic of dairy cattle as they help to estimate the diagnosis of AA [1,2,8,28].

There are two suitable sites for abdominocentesis. One of them is on the left or right side of the caudal quadrant of the abdomen, in front of the udder insertion and above the mammary vein. The other is in the cranial quadrant. If it is performed in this quadrant, the puncture should be made $5 \mathrm{~cm}$ caudal to the xiphoid process. In case of doubt, an ultrasound-guided puncture will facilitate the procedure due to the scarce fluid in the peritoneal cavity [29]. It should be noted that the absence of peritoneal fluid in the abdominal cavity in cattle does not exclude peritonitis $[4,17]$.

Peritoneal fluid can be evaluated macroscopically for turbidity, colour, odour, and volume. Under normal conditions the PF has low turbidity. However, an increase in turbidity indicates the presence of inflammatory cells, blood, and proteins [30]. The dark or intense colour of the PF is suggestive of the involvement of the abdominal cavity [31]. If a portable refractometer is available, both the amount of protein and density can be measured. Peiró et al., [32] attributed the increase in PF density (above $1.015 \mathrm{~g} / \mathrm{mL}$ ) to the local inflammatory process installed in the abdominal cavity not present in healthy animals. Concerning protein, mean values above $3.0 \mathrm{~g} / \mathrm{dL}$ could be indicative of peritonitis. The odour of the sample can also provide useful information: if it smells like urine, we may be dealing with a case of uroperitoneum (Table 2).

Table 2. Classification and origin of peritoneal fluid according to protein $(\mathrm{g} / \mathrm{dL})$ and cell concentration in the modified peritoneal fluid.

\begin{tabular}{ccr}
\hline Modified Peritoneal Fluid & Protein and Cell Concentration & Origin \\
\hline Trasudate & $<2.5$ g protein $/ \mathrm{dL} \mathrm{y}<5000$ cells $/ \mathrm{mL}$ & $\begin{array}{c}\text { hypoproteinemia, renal failure, parasite infestation, } \\
\text { chronic diarrhoea }\end{array}$ \\
\hline Modified transudate & $2.5-3 \mathrm{~g}$ protein $/ \mathrm{dL}$ y & displacement of abomasum, pericarditis, neoplasm \\
\hline Exudate & $5000-10,000$ cells $/ \mathrm{mL}$ & $50 \%$ of neutrophils, infectious peritonitis \\
\hline
\end{tabular}

The cytological and microbiological study should be performed in the laboratory. However, first and valuable information can already be obtained on the farm.

\subsection{Abdominal Ultrasonography}

Abdominal ultrasound is an immediate and imaging procedure that captures images in real-time. Currently, ultrasonography together with laboratory tests has become part of the diagnosis of the acute abdomen [33]. The main purpose of ultrasonography in the abdominal cavity is to determine which diseases can be managed with medical treatment and which require emergency surgery [3]. 
This technique is indicated to localize the lesion better or to confirm a clinical diagnosis, traumatic reticuloperitonitis, intestinal obstruction, abomasal displacement, and the presence of abscesses in abdominal organs [3].

The ultrasound examination should not be limited to the area of the suspected lesion. Instead, it should always be a systematic, complete, and orderly examination, with the intention of not overlooking important findings [33]. It starts on the left side at the level of the reticulum and continues in a caudal direction, with the evaluation of the spleen and rumen. Then the right side is evaluated, starting from caudal to cranial, through the small and large intestine, then the right kidney, liver, omasum, and abomasum. In all these viscera, the structure of the wall, its size, content, and sometimes its functionality is evaluated [34].

\subsubsection{Reticulum}

Ultrasound of the reticulum is performed on both sides of the thorax. We must bear in mind that this technique does not visualize contents of the reticulum or the complete structure of its wall [35]. However, it allows us to evaluate its motility as well as the surrounding structures. We can detect the presence of abscesses, fluid, or perireticular fibrin [36]. To evaluate reticular motility, it is necessary to observe reticular movements for three minutes [37]. In the case of reticuloperitonitis (Figure 1), in addition to detecting the presence of free fluid and fibrin deposits, we may find that the frequency and amplitude of the contractions decrease due to the adhesions present [35-38].

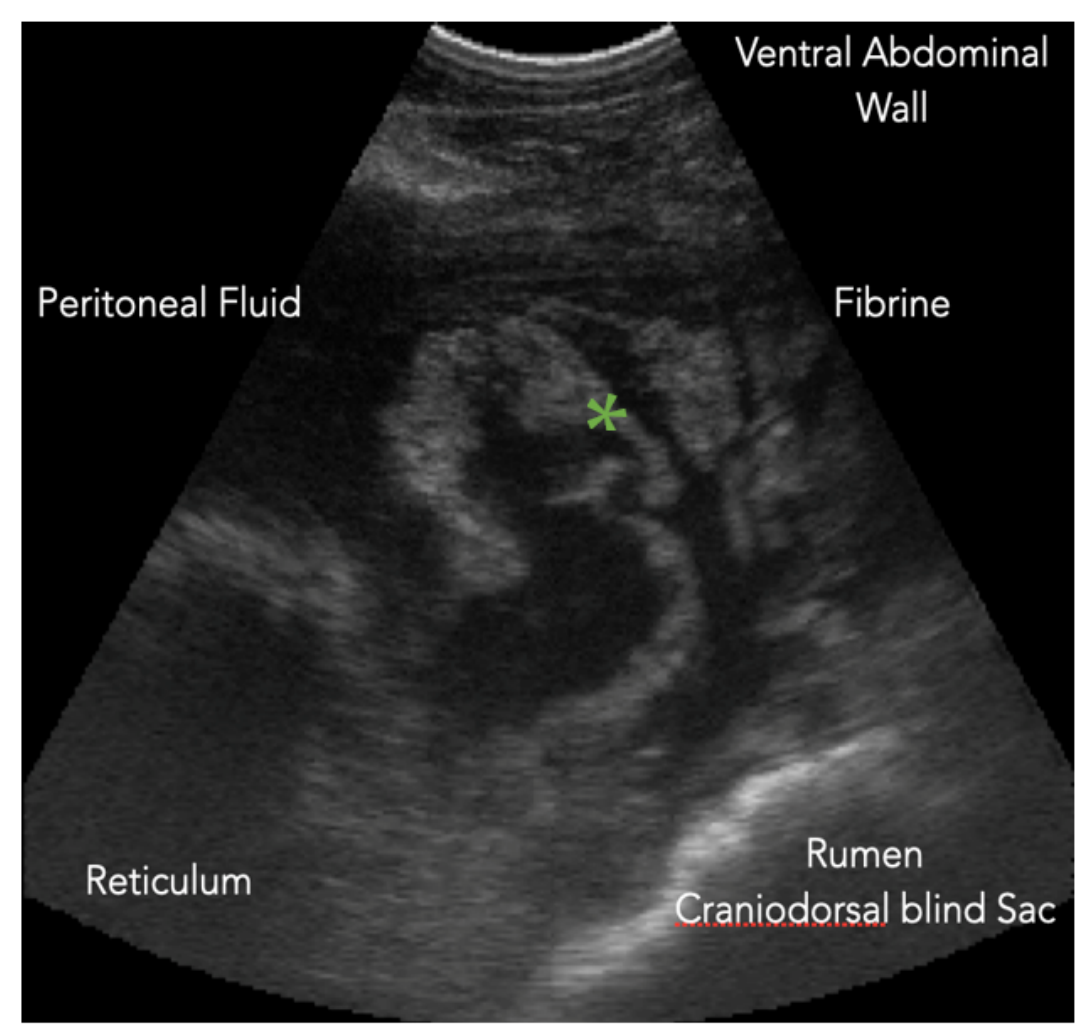

Figure 1. Infectious reticuloperitonitis, thickened reticulum wall, fibrin, and peritoneal fluid are observed * (With permission Giovanni Gnemmi).

\subsubsection{Rumen}

As with the reticulum, only the wall of the rumen is visible but not the rumen content. If there is suspicion of peritonitis, we can confirm it by the presence of fibrin in the rumen sulcus [38]. 


\subsubsection{Omasum}

The omasum offers an ultrasound image similar to the reticulum, although the omasum presents a thicker wall and absence of contractions [39]. The usefulness of ultrasonography on this structure is questionable. The results of a study [40] in cows with abomasal displacement, abomasal volvulus, and paralytic ileus showed that the sonographic appearance of the omasum was similar for sick and healthy cows [40]. As the only exception, we point out that in cases of reticulo-omasal stenosis some degree of motility is found [41].

\subsubsection{Abomasum}

Ultrasonography allows us to evaluate its position, size, and content. It has a much thinner wall than the rest of the pre-stomachs, so it is sometimes difficult to visualize it. For its identification, we can first locate the pylorus, which has a thicker wall and is half-moon-shaped located cranial to the duodenum [42] (Figure 2).

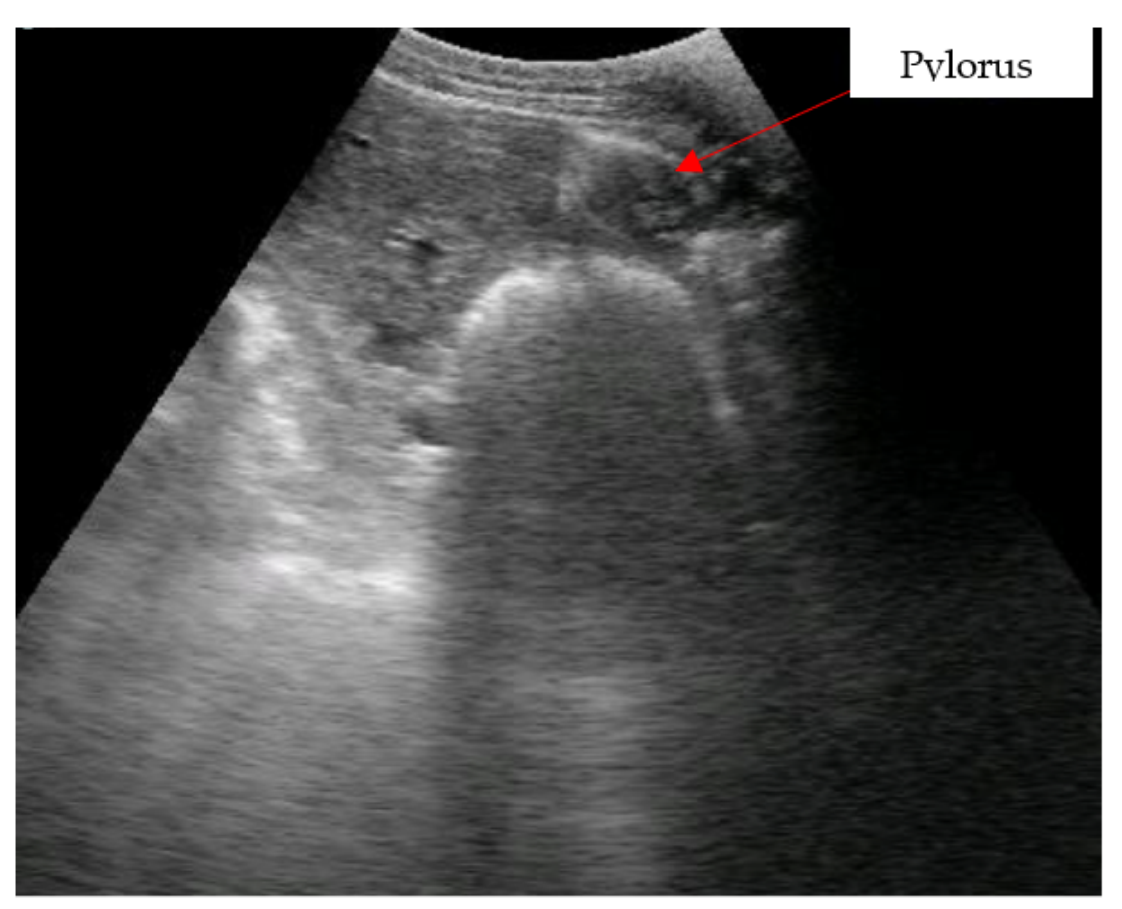

Figure 2. Image of the crescent-shaped pylorus, with a thickened wall that makes it possible to locate it and from there to visualize the contents of the rest of the abomasum. (With permission Giovanni Gnemmi).

We must keep in mind that the physiological position of the abomasum varies according to the stage of pregnancy: at the end of it, it is located towards the left side, and after delivery, it returns to the right [42].

When abomasal displacement is suspected, the pylorus is found medial to the right mammary vein or near the ventral midline (Table 3). For this pathology, ultrasonography helps in clinical decision making. The incapacity to visualize the liver will indicate that we are dealing with a distended abomasum [41].

If volvulus is suspected, it is advisable to pay attention to the pylorus position, which will be in a more cranial orientation than usual [42]. Finally, abomasal ulcers cannot be detected by ultrasound [43]. Even if the ulcer perforates the abomasum, it can be misinterpreted as peritonitis [43].

\subsubsection{Intestine}

Intestinal ultrasound allows us to assess the diameter of the intestinal loops and their motility [34] (Table 3). Any alteration in either of these parameters helps us to determine whether there is good peristalsis or the existence of paralytic ileus. 
Table 3. The complementary tests necessary for the diagnosis of the pathologic process susceptible to causing an acute abdominal syndrome.

\begin{tabular}{l}
$\begin{array}{l}\text { Gastrointestinal Visceras } \\
\text { Disease }\end{array}$ \\
\hline
\end{tabular}

\begin{tabular}{lll}
\hline Abomasal volvulus & - & $\begin{array}{l}\text { serum biochemistry: hypocloremia, metabolic alkalosis, and metabolic acidosis } \\
\text { may be superimposed if it is durable over time. } \\
\text { abdominal ultrasonography: abomasal distension and the pylorus position, } \\
\text { which will be in a more cranial orientation than usual. }\end{array}$ \\
\hline Abomasal displacement & $-\quad \begin{array}{l}\text { serum biochemistry: hypocloremia, alkalosis. } \\
\text { abdominal ultrasonography: allows us to evaluate its position, size, and content. } \\
\text { It has a much thinner wall than the rest of the pre-stomachs, when the } \\
\text { abomasum is displaced, the pylorus is found medial to the right mammary vein } \\
\text { or near the ventral midline. }\end{array}$ \\
\hline Hemorrhagic jejunitis & $-\quad \begin{array}{l}\text { serum biochemistry: metabolic acidosis with variable electrolyte status. } \\
\text { abdominal ultrasonography: the intestinal loop contents appear hyperechoic } \\
\text { due to the presence of blood. } \\
\text { isolation of the causative agent. }\end{array}$ \\
\hline Intussusception & $\begin{array}{l}\text { serum biochemistry: hypochloremia, hyponatremia, hypokalemia. } \\
\text { abdominal ultrasonography: loops of intestine in right paralumbar fossa and } \\
\text { right ventral abdomen are dilated, the intussusception is sometimes not possible } \\
\text { to visualize. }\end{array}$ \\
\hline
\end{tabular}

- $\quad$ serum biochemistry: hyperglycemia, hyponatremia, hypochloremia,

Mesenteric torsion hypokalemia, azotemia.

- $\quad$ abdominal ultrasonography: distended bowel loops before the obstruction point.

\begin{tabular}{lll}
\hline Non Gastrointestinal Visceras Disease & Complementary Diagnostic Methods \\
\hline Uroliths & - & $\begin{array}{l}\text { serum biochemistry: mild azotemia, if bladder and urethra are intact. } \\
\text { transrectal ultrasonography allows us to visualize the state of the bladder, } \\
\text { whether it is intact and the presence of uroliths, appear as hyperechogenic } \\
\text { masses. }\end{array}$
\end{tabular}

- $\quad$ urinalysis: dipstick (hematuria and proteinuria) and sediment examination (bacteriuria, hematuria, and pyuria)

- haematological and biochemical findings: dehydrated, azotemia, and if it is

Pyelonephritis chronic anemia and hypoalbuminemia.

- $\quad$ renal ultrasonography: hyperechogenic areas are visualized in the calyx and renal sinus.

Uterine torsion none usually necessary, vaginal and rectal palpation confirms the diagnosis.

- $\quad$ serum biochemistry: elevations in the serum activity of ALP, AST, GGT, SDH, and total bilirubin.

Cholestasis

- $\quad$ liver ultrasonography: hepatomegaly and bile duct dilation, the echogenicity of the hepatic parenchyma is increased.

- $\quad$ The guided ultrasonographic biopsy: will give us a definitive diagnosis.

Obstruction of ileus or intussusception is difficult to diagnose sonographically. At most, we can observe distended bowel loops before the obstruction point. In the case of JHS, the intestinal loop contents appear hyperechoic due to the presence of blood [44].

Although ultrasound of the large intestine can be performed in the dorsal part of the right flank to detect pathology at the level of the cecum, the ideal way is the transrectal palpation to make a correct diagnosis $[41,45,46]$. 


\subsubsection{Liver}

Ultrasonography detects parenchymal alterations such as abscesses [47]. It is a recognizable finding in adult cows with hepatic lipidosis, with a high body condition score [48] as well as in the presence of chronic fasciolosis [40]. The guided ultrasonographic biopsy will give us a definitive diagnosis (Figure 3). However, the previous examination of the animal in terms of deworming patterns, diet, or body condition, can serve as a reference.

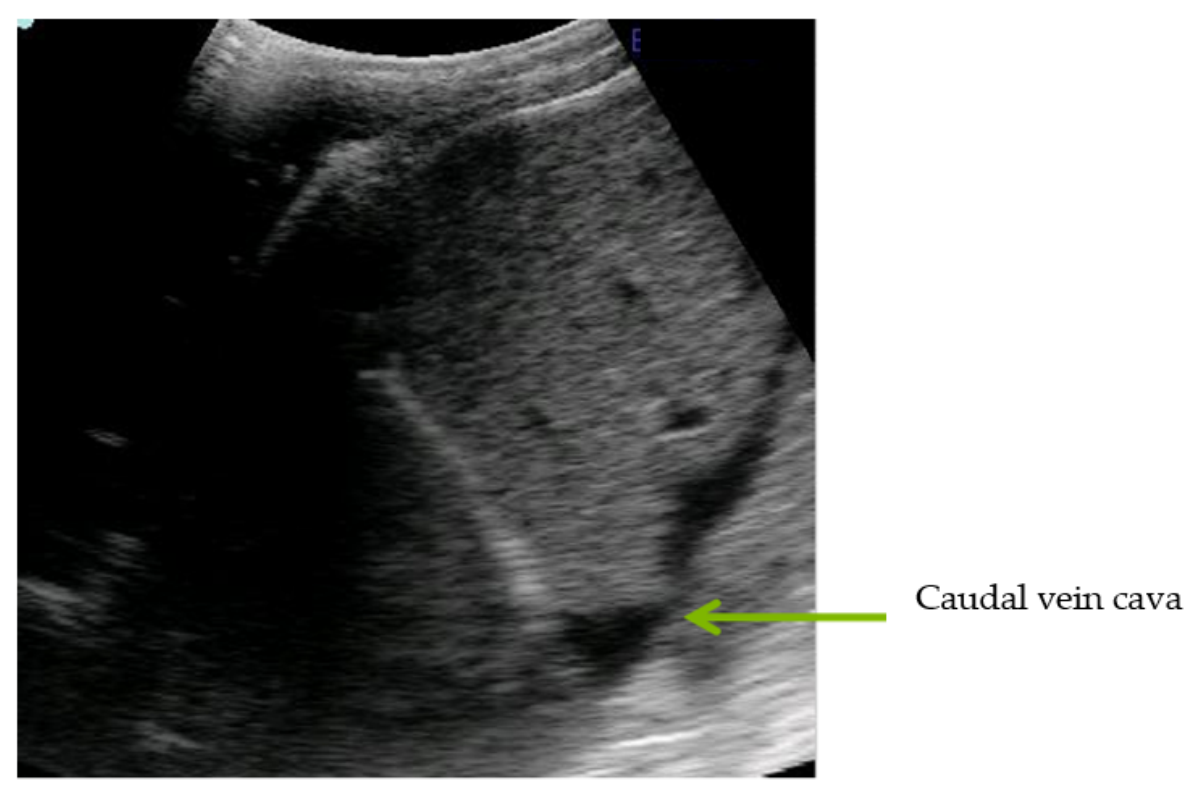

Figure 3. Homogeneous and hypoechoic liver, parenchyma and anechogenic vessels, and caudal vein cava located in the 10th-11th intercostal space. (With permission Giovanni Gnemmi).

Another visualizable disorder, and cause of AA, is the presence of cholestasis, by visualizing both the bile ducts and the gallbladder [34].

\subsubsection{Urinary Tract}

In cattle, urinary tract diseases are less frequent than gastrointestinal, respiratory, or musculoskeletal disorders [49].

The most frequent urinary abnormality in cattle is pyelonephritis. In this case, hyperechogenic areas are visualized in the calyx and renal sinus (Figure 4) [50,51]. This process can be uni or bilateral, with a poor prognosis if the animal presents bilateral pyelonephritis.

The presence of renal cysts or uroliths is a visible finding on urinary ultrasound (Table 3). Uroliths appear as hyperechogenic masses [52,53]. The presence of cystitis is detected with transrectal ultrasonography. The healthy bladder has a thin, smooth wall and anechogenic contents; in case of infection, the wall will be thicker and its contents will be more echogenic [52].

\section{Conclusions}

From our clinical point of view, when facing an acute abdomen, the following premises should be taken into account:

The most important point is to remain calm, despite being faced with a clinical or surgical emergency, with limited technical means and personnel.

The clinical history and a complete physical examination are the first steps to be taken in order to reach a diagnosis.

It is necessary to have several ancillary tests in situ, considering the emergency of the patient and the need to intervene as soon as possible: sometimes, the urgency is such that it is necessary to intervene before stabilizing the patient. Ultrasound, abdominal fluid analysis, and biochemical tests, in this order of importance, can help us to confirm the diagnosis, localize it, and assess the extent of AA. 


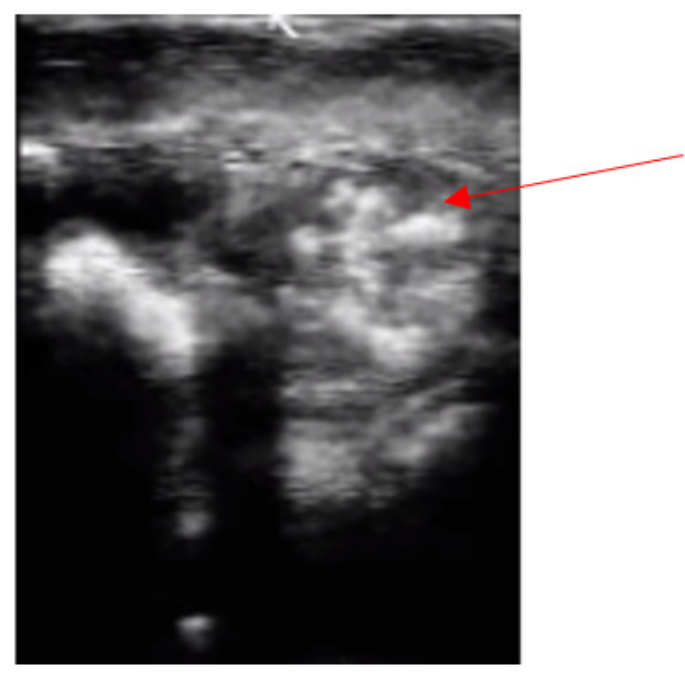

\section{Hyperechogenic \\ areas in the calyx \\ and renal sinus}

Figure 4. Longitudinal image of kidney with pyelonephritis. (With permission Giovanni Gnemmi). A compilation of all the above-mentioned details.

Author Contributions: Conceptualization R.M., J.H., C.C.; methodology J.H.; resources C.C. writing R.M., J.H., C.C.; visualization, J.H.; supervision, J.H., C.C. All authors have read and agreed to the published version of the manuscript.

Funding: This research received no external funding.

Institutional Review Board Statement: Not applicable, due to our clinical veterinary practice. All the information provided in this article is the result of clinical experience over more than 20 years, as well as the study and comparison of different bibliographic sources.

Informed Consent Statement: Not applicable.

Data Availability Statement: No new data were created or analysed in this study.

Acknowledgments: The authors would like to thank Giovanni Gnemmi, Bovinevet International Bovine Ultrasound Services \& Herd Management, Zaragoza, Spain, for his contribution with ultrasound images to improve the quality of this manuscript.

Conflicts of Interest: The authors declare no conflict of interest. The present affiliations that are mentioned in the author list had no role in the design of the study; in the collection, analyses, or interpretation of data; in the writing of the manuscript, or in the decision to publish the results.

\section{References}

1. Dos Santos, J.F.; Otaviano do Rego, R.; Bastos Afonso, J.A.; Jurandir, J.; Silva, P.C.; Soares, P.C.; Lopes de Mendoça, C. Hematologic response and serum and peritoneal fluid proteinogram of cattle affected by intestinal diseases and traumatic reticuloperitonitis. Semin. Ciências Agrárias 2021, 42, 209-228. [CrossRef]

2. Walters, P.C. Approach to the acute abdomen. Clin. Tech. Small Anim. Pract. 2000, 15, 63-69. [CrossRef] [PubMed]

3. Braun, U. Ultrasound as a Decision-Making tool in Abdominal surgery in cows. Vet. Clin. N. Am. Food Anim. Pract. 2005, 21, 33-53. [CrossRef]

4. Fecteau, G.; Derochers, A.; Francoz, D.; Nichols, S. Diagnostic Approach to the Acute Abdomen. Vet. Clin. Food Anim. 2017, 34, 19-33. [CrossRef] [PubMed]

5. Van Metre, D.C.; Callan, R.J.; Holt, T.N.; Garry, F.B. Abdominal emergencies in cattle. Vet Clin. N. Am. Food Anim. Pract. 2005, 21, 655-696. [CrossRef]

6. Wittek, T.; Constable, P.D.; Morin, D.E. Abomasal impaction in Holstein-Friesian cows: 80 cases (1980-2003). J. Am. Vet. Med. Assoc. 2005, 15, 287-291. [CrossRef]

7. Frazer, G.S.; Perkins, N.R.; Constable, P.D. Bovine uterine torsion: 164 hospital referral cases. Theriogenology 1996, 46, 739-758. [CrossRef]

8. Callan, R.; Jones, M. Digestive Disorders in Ruminants. Vet. Clin. N. Am. Food Anim. Pract. 2017, 33, ix-x. [CrossRef]

9. Snyder, E.; Credille, B. Diagnosis and Treatment of Clinical Rumen Acidosis. Vet Clin. Food Anim. 2017, 33, 451-461. [CrossRef]

10. Abegg, R.; Eicher, R.; Lis, J.; Lischer, C.J.; Scholtysik, G.; Steiner, A. Concentration of volatile fatty acids in digesta samples obtained from healthy cows and cows with cecal dilatation or dislocation. Am. J. Vet Res. 1999, 60, 1540-1545. 
11. Sodhi, H.S.; Shukla, V.K. Bovine intestinal obstruction: A review. Pharma Innov. 2021, 10, 1099-1104.

12. Elhanafy, M.M.; French, D.D.; Braun, U. Understanding jejunal hemorrhage syndrome. J. Am. Vet. Med. Assoc. 2013, 243, 352-358. [CrossRef] [PubMed]

13. Berghaus, R.D.; McCluskey, B.J.; Callan, R.J. Risk factors associated with hemorrhagic bowel syndrome in dairy cattle. J. Am. Vet. Med. Assoc. 2005, 226, 1700-1706. [CrossRef]

14. Abutarbush, S.M.; Radostits, O. Jejunal hemorrhage syndrome in dairy and beef cattle: 11 cases (2001 to 2003). Can. Vet. J. 2005, 46, 711-715.

15. Dennison, A.C.; van Metre, D.C.; Callan, R.J.; Dinsmore, P.; Mason, G.L.; Ellis, R.P. Hemorrhagic bowel syndrome in dairy cattle: 22 cases (1997-2000). J. Am. Vet. Med. Assoc. 2002, 221, 686-689. [CrossRef] [PubMed]

16. Pearson, H.; Pinsent, P.J. Intestinal obstruction in cattle. Vet. Rec. 1977, 101, 162-166. [CrossRef]

17. Pearson, H. Uterine torsion in cattle: A review of 168 cases. Vet. Rec. 1971, 89, 597-603. [CrossRef]

18. Meylan, M. Abdome acuto in vacche e vitelli: Gestione del caso clínico, diagnosi e terapia. In Proceedings of the Congreso Internazionale SIVAR, Cremona, Italy, 10-12 May 2012; pp. 48-52.

19. Buczinski, S.; Dore, E.; Boulay, G.; Francoz, D. Validation of the handheld Lactate-Pro analyzer for measurement of blood l-lactate concentration in cattle. Vet. Clin. Pathol. 2014, 43, 567-572. [CrossRef]

20. Giertzuch, S.; Lorch, A.; Lausch, C.K.; Knubben-Schweizer, G.; Trefz, F.M. Prognostic utility of pre- and postoperative plasma 1-lactate measurements in hospitalized cows with acute abdominal emergencies. J. Dairy Sci. 2020, 103, 11769-11781. [CrossRef]

21. Pang, D.S.; Boysen, S. Lactate in veterinary critical care: Pathophysiology and management. J. Am. Anim. Hosp. Assoc. 2007, 43, 270-279. [CrossRef]

22. Rosenstein, P.G.; Tennent-Brown, B.S.; Hughes, D. Clinical use of plasma lactate concentration. Part 1: Physiology, pathophysiology, and measurement. J. Vet. Emerg. Crit. Care 2018, 28, 85-105. [CrossRef]

23. Roussel, A.J. Fluid therapy in mature cattle. Vet. Clin. N. Am. Food Anim. Pract. 1999, 15, 545-557. [CrossRef]

24. Meylan, M. Prognostic indicators in cattle with right-sided displacement of the abomasum and abomasal volvulus. Schweiz. Arch. Tierheik. 1999, 141, 413-418.

25. Boulay, G.; Francoz, D.; Doré, E.; Dufour, S.; Veillette, M.; Badillo, M.; Bélanger, A.M.; Buczinski, S. Preoperative cow-side lactemia measurement predicts negative outcome in Holstein dairy cattle with right abomasal disorders. J. Dairy Sci. 2014, 97, $212-221$. [CrossRef]

26. Buczinski, S.; Boulay, G.; Francoz, D. Preoperative and post-operative L-lactatemia assessment for the prognosis of right abomasal disorders in dairy cattle. J. Vet. Intern. Med. 2015, 29, 375-380. [CrossRef] [PubMed]

27. Nazifi, S.; Ansari-Lari, M.; Asadi-Fardaqi, J.; Rezaei, M. The use of receiver operating characteristic (ROC) analysis to assess the diagnostic value of serum amyloid A, haptoglobin and fibrinogen in traumatic reticuloperitonitis in cattle. Vet. J. 2009, 182, 315-319. [CrossRef] [PubMed]

28. Zadnik, T. A retrospective study of peritoneal fluids in cows with abdominal disorders. Vet. Glas. 2010, 64, 187-195. [CrossRef]

29. Braun, U. Ascites in cattle: Ultrasonographic findings and diagnosis. Vet. Clin. N. Am. Food Anim. Pract. 2016, 32, 55-83. [CrossRef]

30. Fecteau, G. Peritonitis in Ruminants, chapter 32 Diseases of the alimentary tract. In Large Internal Medicine, 6th ed.; Bradford, P.S., van Metre, D.C., Pusterla, N., Eds.; Elsevier: St. Louis, MO, USA, 2020; pp. 879-883.

31. Dezfouli, M.R.M.; Lotfollahzadeh, S.; Sadeghian, S.; Kojouri, G.A.; Eftekhari, Z.; Khadivar, F.; Bashiri, A. Blood electrolytes changes in peritonitis of cattle. Comp. Clin. Path. 2012, 21, 1445-1449. [CrossRef]

32. Peiró, J.R.; Lucato, B.; Mendes, L.C.N.; Ciarlini, P.C.; Feitosa, F.L.F.; Bonelho, F.L.; Maemura, S.M.; Soares, G.T.; Santana, A.E.; Perri, S.H.V. Evaluation of cytologic and biochemical variables in blood, plasma, and peritoneal fluid from calves before and after umbilical herniorraphy. Am. J. Vet. Res. 2009, 70, 423-432. [CrossRef]

33. Vaughan, B. Ruminant Abdominal Ultrasonography, chapter 32 Diseases of the alimentary tract. In Large Internal Medicine, 5th ed.; Bradford, P.S., Ed.; Elsevier: St. Louis, MO, USA, 2015; pp. 767-777.

34. Gerspach, C. Ultrasonogrhaphic evaluation of the acute abdomine in cattle. In Proceedings of the XXIV International Congress on Bovine Medicine, Sevilla, Spain, 22-24 May 2019; pp. 63-64.

35. Braun, U.; Gotz, M.; Marmier, O. Ultrasonographic findings in cows with traumatic reticuloperitonitis. Vet. Rec. 1993, 133, 416-422. [CrossRef] [PubMed]

36. Braun, U.; Gerspach, C.; Warislohner, S.; Nuss, K.; Ohlerth, S. Ultrasonographic and radiographic findings in 503 cattle with traumatic reticuloperitonitis. Res. Vet. Sci. 2018, 119, 154-161. [CrossRef]

37. Braun, U.; Gerspach, C.; Ohlerth, S.; Warislohnera, S.; Nussa, K. Aetiology, diagnosis, treatment and outcome of traumatic reticuloperitonitis in cattle. Vet. J. 2020, 255, 105424. [CrossRef] [PubMed]

38. Braun, U.; Flückiger, M.; Götz, M. Comparison of ultrasonographic and radiografphic findings in cows with traumatic reticuloperitonitis. Vet. Rec. 1994, 135, 470-478. [CrossRef]

39. Braun, U.; Blessing, S. Ultrasonographic examination of the omasum in 30 healthy cows. Vet. Rec. 2006, 159, 812-815.

40. Braun, U.; Blessing, S.; Lejeune, B.; Hässig, M. Ultrasonography of the omasum in cows with various gastrointestinal diseases. Vet. Rec. 2007, 160, 865-869. [CrossRef]

41. Buczinski, S. Ultrasonography of the ruminant abdomen, Chapter 32 Diseases of the alimentary tract. In Large Internal Medicine, 6th ed.; Bradford, P.S., van Metre, D.C., Pusterla, N., Eds.; Elsevier: St. Louis, MO, USA, 2020; pp. 838-847. 
42. Buczinski, S.; Belanger, A.M.; Francoz, D. Ultrasonographic appearance of lymphomatous infiltration of the abomasum in cows with lymphoma. J. Am. Vet. Med. Assoc. 2011, 238, 1044-1047. [CrossRef] [PubMed]

43. Gerspach, C.; Oschlies, C.; Kuratli, J.; Braun, U. Ultrasonographic documentation of type-3 abomasal ulcer in a cow with left displacement of the abomasum. Acta Vet. Scandinavica 2020, 62, 29. [CrossRef]

44. Braun, U.; Nuss, K.; Knubben-Schweizer, G.; Gerspach, C. The use of ultrasonography for diagnosing the cause of colic in cows. A review. Tierarztl. Prax. Ausg. G Grosstiere 2011, 39, 289-298.

45. Braun, U.; Amrein, E.; Koller, U. Ultrasonographic findings in cows with dilatation, torsion and retroflexion of the caecum. Vet. Rec. 2002, 150, 75-79. [CrossRef]

46. Braun, U. Ultrasonography of the liver in cattle. Vet. Clin. N. Am. Food Anim. Pract. 2009, 25, 591-609. [CrossRef]

47. Liberg, P.; Jonsson, G. Ultrasonography and determination of proteins and enzymes in blood for the diagnosis of liver abscesses in intensively fed beef cattle. Acta Vet. Scand. 1993, 34, 21-28. [CrossRef]

48. Starke, A.; Haudum, A.; Weijers, G.; Herzog, K.; Wohlsein, P.; Beyerbach, M.; de Korte, C.L.; Thijssen, J.M.; Rehage, J. Noninvasive detection of hepatic lipidosis in dairy cows with calibrated ultrasonographic image analysis. J. Dairy Sci. 2010, 93, 2952-2965. [CrossRef]

49. Floeck, M. Ultrasonography of bovine urinary tract disorders. Vet. Clin. Food Anim. 2009, 25, 651-667. [CrossRef]

50. Hayashi, H.; Biller, D.S.; Rings, D.M.; Miyabayashi, T. Ultranonographic diagnosis of pyelonephritis in a cow. J. Am. Vet. Med. Assoc. 1994, 205, 736-738.

51. Floeck, M. Sonographic application in the diagnosis of pyelonephritis in cattle. Vet. Radiol. Ultrasound. 2007, 48, 74-77. [CrossRef]

52. Hoque, M.; Somvanshi, R.; Singh, G.R.; Mogha, I.V. Ultrasonographic evaluation of urinary bladder in normal, fern fed and enzootic bovine haematuria-affected cattle. J. Vet. Med. A Physiol. Pathol. Clin. Med. 2002, 49, 403-407. [CrossRef]

53. David, C.; Robert, J.; Timothy, N.H.; Franklyn, B.G. Abdominal emergencies in cattle. Vet. Clin. Food Anim. 2005, 21, 655-696. 